the Senior Tutor, and not Cockcroft, to be their Master. The upshot was a turn in his career, a definitive turn to Whitehall and national affairs. It is interesting to speculate whether, if he had gone back to Cambridge then, he would have played a comparable part in first national and later international affairs (though in a less definitive way he was already embarked on both.) $\mathrm{He}$ was persuaded to join the Defence Research Policy Committee. As a committee-member in the conventional sense, he was practically a non-starter, for the simple reason that he rarely said anything; but that didn't mean he was not cogitating, participating and resolving on action. His action took place outside the committee-room, in private meetings with the members and other people one at a time. "I flit from office to office", he wrote in amusingly candid self-observation - and with a spark of literary talent.

In his days at the Cavendish Laboratory in Cambridge, Cockcroft's colleagues had remarked on his extraordinary gift for switching his full concentrated attention from one objective to another, usually with desired, tangible results in each. This gift served henceforward in affairs, national and international. He flitted from office to office, in London, Washington and Moscow; helping to render balances unupsettable while determinedly edging them in the direction of reason and sanity. It was in his earlier concern with promoting the flow of knowledge, about developments in atomic science, between his own country and the United States that, despite the American preoccupation with secrecy, he began to win the confidence of Washington: through the revival of his old friendship with Rutherford's Russian protégé, Kapitza, he began, against the tide of Russian suspicion, to win the confidence of Moscow. Needless to say he did not get all he wanted, but what he did get was important to all three countries, because it sprang from a deep feeling for human beings and human society in general, for the community of nations. Having been one of the main instigators in establishing in his own country the peaceful use of atomic energy for generating power, he began to speak out for control of nuclear arsenals, playing a part in bringing about the Test Ban Treaty. His political - and moral - stance is splendidly defined at the conclusion of Oliphant's tribute to him:

In politics he was an old-fashioned liberal, seeking always the middle way of decency and fairness. If he was intolerant in any way, it was of inhumanity, the greed and self-seeking of both the extreme right and the extreme left. He never sought power, but when it came to him, he exercised it with wisdom and restraint.

William Cooper is the pseudonym of the novelist Harry Hoff; his most recent book is Scenes from Later Life (Macmillan, London, 1983). From 1958 to 1972 he was personnel consultant to the United Kingdom Atomic Energy Authority and the Central Electricity Generating Board.

\section{A feeling for the unfathomable}

\section{Martin Gardner}

Reality and Empathy: Physics, Mind and

Science in the 21st Century.

By Alex Comfort.

State University of New York Press:

1984. Pp.272. Hbk \$39.50; pbk \$12.95.

DR Alex Comfort, trained in classics at Cambridge University, is the British gerontologist who made a fortune with his bestsellers The Joy of Sex and More Joy of Sex. Discussions with bright students at the Neuropsychiatric Institute, University of California at Los Angeles, where Comfort now teaches, impelled him to set down on paper the ideas that have swirled in his brain since he discovered the joy of QM (quantum mechanics).

Comfort's main theme, like that of many another recent book, is that QM is such a revolutionary new way of looking at the Universe that if it could be "popularly empathized, it would be a blockbuster" (p.25). By "empathize" Comfort means made so intuitively clear that nonphysicists could feel what it is all about.

The book's first sentence, "Worlds are created by brains", is intentionally ambiguous. You quickly learn that "world" means a world-model, or map, of reality, but later on you encounter the view that perhaps brains have created the outside world as well. Objective reality and mind could be related by what Douglas Hofstadter calls a "strange loop". Somehow - just how is the ultimate mystery - Being was able to bifurcate into matter and minds that allow the matter to see itself. Matter and mind may be epiphenomena of one another, like Escher's picture of two hands, each sketching the other.

Comfort professes to be immune to the epidemic of "pseudo-east nonsense" now infecting the West - what he calls a mix of "Aquarians, acid-heads, and amateur mystics", speaking "yoga-babble" and tossing up "premature Taoists who write popular books on physics"' (pp.37-38). The public would do well to stop listening to "itinerant swamis who preach in mottos out of fortune cookies" (p.33), and turn instead to the original sacred literature of Buddhism and Hinduism where they would find that introspection had indeed produced visions in surprising harmony with the empirical results of modern physics.

What do QM and Eastern thought have in common? Comfort believes it is a way of seeing our pluralistic phenomenal world as an illusion produced by an impenetrable, timeless, unfathomable reality. Comfort seldom calls this reality God, preferring instead the impersonal Brahman of Hinduism. Although QM makes no onto-

logical statements, it is nevertheless saturated with anomalies that Comfort thinks support this Eastern insight.

Consider the notorious EPR (EinsteinPodolsky-Rosen) paradox, invented by Einstein and two associates as a thought experiment, but which recently has received strong support from laboratory experiments. Two photons (in one version) are emitted in opposite directions by an interaction that gives them opposing spins. In QM, neither particle has a definite spin until measured, yet the two are so correlated that if you measure $A$, thereby creating, say, a plus spin, $B$ will acquire a minus spin even though it may be light years away. It is worse than that. If $\boldsymbol{A}$ is measured a second time, it again will acquire plus or minus spin with equal probability. If the spin alters, the companion particle instantly changes to the opposite spin. It is like tossing someone a glove, Comfort writes, then if you turn the companion glove inside out, the other glove will at once invert to preserve the pair's opposite handedness.

Einstein believed that his paradox proved the incompleteness of QM. Comfort agrees. The best way out, he thinks, is to adopt what he calls the "thingless universe" of David Bohm, a QM expert who has long been an admirer of Eastern philosophy. In Bohm's vision, particles are "explicates" of an "implicate order", a substrate that is outside our space and time. Comfort likens the particles to Proceedings

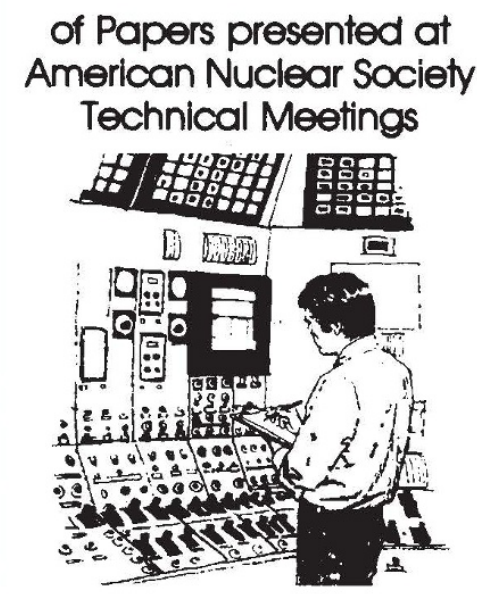

write for free Publications and Services Catalog.

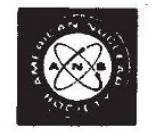

American Nuclear Society 555 N. Kensington Ave. La Grange Park, IL 60525 (312) $352-1661$ 

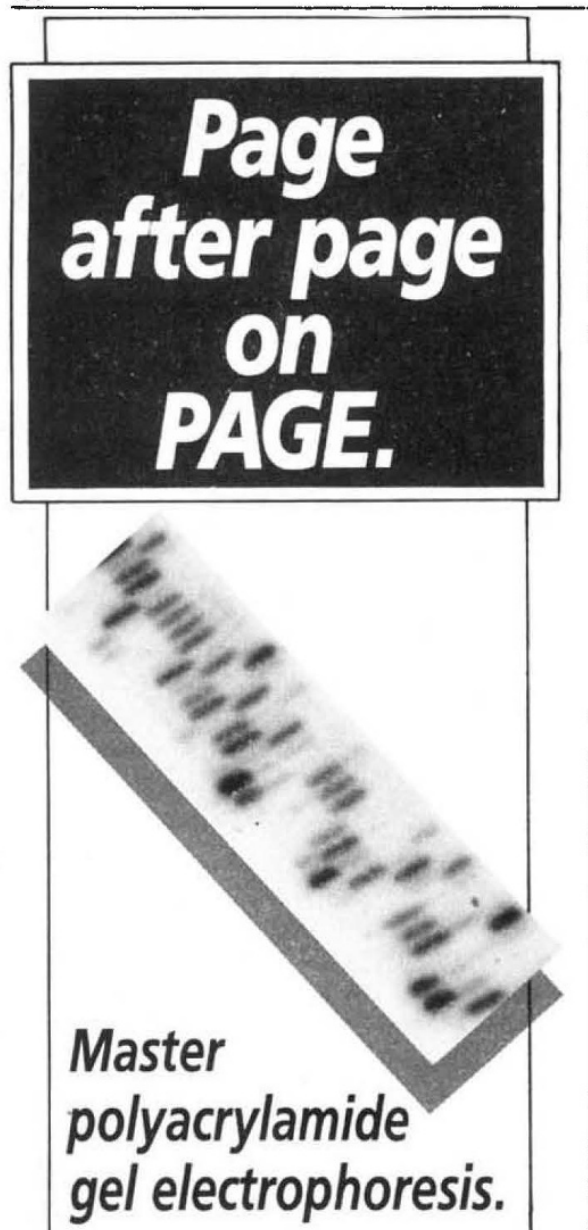

You don't need to be a polymer chemist to master polyacrylamide gel electrophoresis (PAGE). At least not if you have Bio-Rad's new Technical Bulletin 1156, entitled "Acrylamide Polymerization - a Practical Approach." It includes page after page of useful information on such topics as - critical parameters - polymerization protocols - polymerization analysis - handling of gel reagents. Also a section on troubleshooting! With this document to help you, the novice can master PAGE and the experienced user can optimize separations

even further.

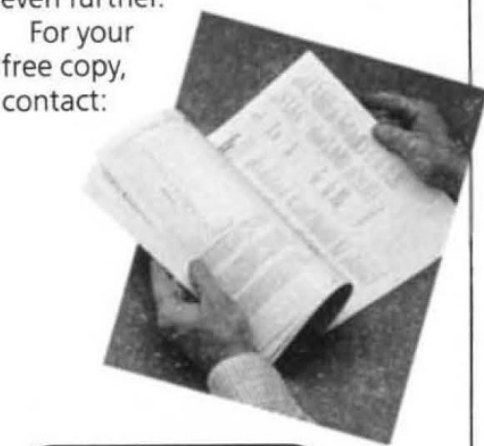

BIORAD

Bio-Rad Laboratories -

Chemical Division

2200 Wright Avenue

Richmond, CA 94804

(415) $234-4130$ spots that seem to move on the screen of a computer game. But nothing is really moving. Points of light are merely switching on and off in obedience to signals from invisible hardware. Perhaps Zeno was right. Motion is unreal. The outside world is what the Hindus call maya, an illusion conjured up by the motionless Brahman.

It is easy to see how this vision could furnish support for the psi forces that parapsychologists claim are indifferent to space and time. Comfort makes a great pother about his neutrality with respect to psi: "I have no idea whether paranormal phenomena exist or not"' (p.229). However, he is a vigorous advocate of what he calls "demonic" conjectures - efforts to see the world in "non-human" ways. It may be, he writes, that altered states of consciousness give authentic glimpses into bizarre but fruitful world-models. $\mathrm{He}$ shares with psychoanalyst Jan Ehrenwald, an ardent advocate of psi, the conviction that anecdotal evidence for psi, such as telepathic dreams, is far stronger than any laboratory result. Such evidence is so voluminous, Comfort says, that to attribute all of it to self-deception, coincidence or fraud seems to him like doubting the existence of badgers.

Scientists such as Oliver Lodge, who became Spiritualists, Comfort considers much less credulous than sceptics suppose. They "probably" did not see discarnate spirits, he allows, though they "apparently" did observe "uncanonical transfer of information"' (p.218). These are curious remarks to come from a man who insists that his personal estimate of the odds for psi being genuine are fifty-fifty.

Comfort's fondness for demonic models prompts him to look benignly on many other conjectures that most scientists consider hogwash. Rupert Sheldrake, for instance, is persuaded that members of a species are united by a "morphogenetic field". If you train some rats to find their way through a maze at Harvard University, rats of the same species will learn to run the maze faster in Scotland. Sheldrake may be wrong, Comfort admits, but he is raising an important question. Comfort is pleased that Sheldrake's challenge has not affected

\section{New in paperback}

- Causality and Chance in Modern Physics by David Bohm, with a new preface by the author. Publisher is Routledge \& Kegan Paul, price is £3.95. The book was first published in 1957 and reviewed in Nature 181, 658; 1958.

- Quantum Fields in Curved Space by N. D. Birrell and P. C. W. Davies, published by Cambridge University Press. Price is $£ 13.75$, $\$ 27.95$. For review see Nature 297, 166; 1982.

Lead Pollution: Causes and Control by R. M. Harrison and D. P. H. Laxen, published by Chapman \& Hall in the Science Paperbacks series. Price is $£ 7.95, \$ 23$.

-The Ecology of Algae by F. E. Round, published by Cambridge University Press. Price is $£ 22.50, \$ 39.50$. For review see Nature 297 , $521 ; 1982$. colleagues like an "inopportune flatus in an elevator".

Karl Pribram's holographic model of the brain is another demonic theory that Comfort finds comforting. The Universe may be a monstrous hologram, each tiny part, like one of Leibniz's monads, containing the whole. The book is not yet closed, Comfort is also convinced, on the role of Lamarckism in evolution. His wildest speculation is that sabre-toothed tigers, which flourished before humanity was on the scene, may not have really been "there" except in a vague way, their pale reality sustained only by the low-order brains of the beasts that saw them!

Comfort borrows from Hofstadter the whimsy of interrupting his prose with comic dialogues. A lion and a unicorn step down from a coat of arms to argue about scientific method. A snake named Wilberforce, after the cleric who debated with T.H. Huxley, discusses evolution with a mockingbird. Gezumpstein, a demon from beyond spacetime - his sole task is to invent testable hypotheses - models reincarnation with a row of isolated spots created by painting a line along one side of a helix. Adam demands of God, his psychiatrist, that she reveal the real reason why he was kicked out of Eden.

The cleverest of these interludes tells how Gezumpstein's conjectures take the form of balloons. He distributes them to scientists who blow them up and keep them inflated until they are punctured by a fact. The facts are called "poppers", a play on the name of Karl Popper. Balloons given to mathematicians last the longest, but no balloon is "popper-proof". Many last for centuries before bursting. Some are allowed to deflate, only later to be blown up again.

The book is stimulating, funny, quirky; marred by a rambling, repetitious, disjointed organization. Comfort has a fondness for awkward terms such as "homuncularity," "pre-scientoid" and "dogsbody", a neologism borrowed from James Joyce's Ulysses. He seems to have no interest in any modern Western philosopher except Popper. George Berkeley, who more than any other thinker struggled with all of Comfort's ontological puzzles, is not in the index, though I discovered a trivial reference to him on page 197.

Readers unacquainted with modern physics will find most of the book unintelligible. A section on how each moment of history can be undetermined, even though Brahman is timeless and unchanging - it just is - I found totally opaque. And although I learned much. I finished the book with a dizziness from its endless zigzags, and a feeling that Comfort could have made his points much clearer if he had tried.

Martin Gardner is a science writer. Among other books he is author of The Whys of a Philosophical Scrivener (Harvester, 1983) and Order and Surprise (Prometheus, 1983). 